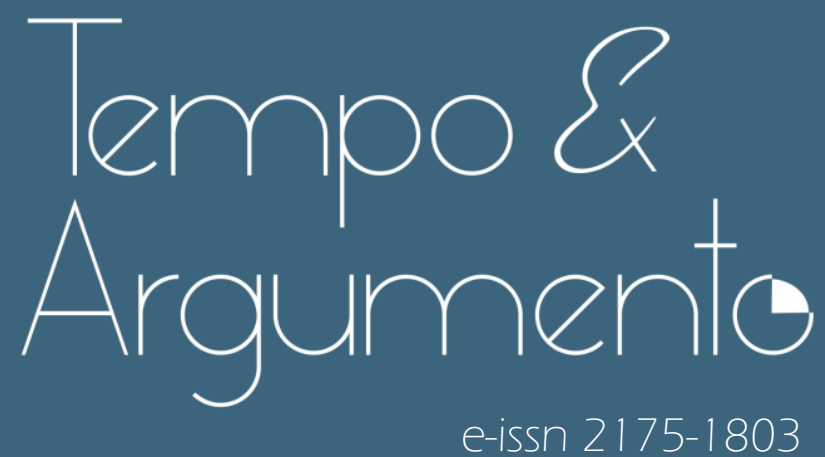

\title{
Aprendizagem conceitual e orientação: uma análise dos estudos da educação histórica em Portugal e no Brasil (2000-2017)
}

- Éder Cristiano de Souza

Doutor em Educação pela Universidade Federal do Paraná (UFPR). Professor Adjunto do curso de História da Universidade Federal da Integração LatinoAmericana (UNILA). Professor permanente do Mestrado em História Social da Universidade Estadual de Londrina (UEL).

Foz do Iguaçu, PR - BRASIL

lattes.cnpq.or/5143188422155351

eder.souza@unila.edu.br

(iD) orcid.org/0000-0001-9835-1711

Para citar este artigo:

SOUZA, Éder Cristiano de. Aprendizagem conceitual e orientação: uma análise dos estudos da educação histórica em Portugal e no Brasil (2000-2017). Tempo e Argumento, Florianópolis, v. 13, n. 33, e0201, maio/ago. 2021.

doi http://dx.doi.org/10.5965/2175180313332021e0201

Recebido: 21/04/2020

Aprovado: $12 / 12 / 2020$ 


\title{
Aprendizagem conceitual e orientação: uma análise dos estudos da Educação Histórica em Portugal e no Brasil (2000-2017) ${ }^{1}$
}

\section{Resumo}

O problema central deste artigo é a relação entre a aprendizagem de conceitos epistemológicos, estruturantes ou de segunda ordem, e a orientação histórica. Se o pressuposto da Educação Histórica é que a apreensão de conceitos mais elaborados, ou sofisticados, qualifica a aprendizagem histórica, como essa aprendizagem contribui para o agir social e a tomada de decisões dos indivíduos? A partir desse questionamento, realizamos um estudo, utilizando como fontes as actas, ou anais, das Jornadas de Educação Histórica, entre 2001-2017. Selecionamos mais de 60 textos, considerados relevantes a partir de critérios definidos para o estudo, efetivando uma análise panorâmica das diversas formas utilizadas pelos diferentes estudiosos para relacionar as duas dimensões que questionamos. Observamos que os estudos da Educação Histórica surgiram a partir da influência inicial dos pesquisadores ingleses, com centralidade da ideia de progressão na aprendizagem dos conceitos epistemológicos, e caminharam gradativamente para um intercâmbio com outras referências e preocupações, como o conceito de consciência histórica. Constatamos que as formas de apropriação e compreensão das relações entre aprendizagem conceitual e orientação temporal foram diversas, com destaque para a presença ainda forte da ideia de progressão conceitual, em Portugal. E, no Brasil, a predominância da ideia de formação da consciência histórica. Por fim, evidenciamos que explorar a relação entre aprendizagem conceitual e orientação histórica é uma questão de certa forma negligenciada, mas também uma possibilidade em aberto, nos estudos sobre aprendizagem histórica nos dois países.

Palavras-chave: Aprendizagem Histórica. Orientação. Consciência Histórica. Literacia Histórica.

\section{Conceptual learning and guidance: an analysis of the Studies of History Education in Portugal and Brazil (2000-2017)}

\begin{abstract}
The central problem of this article is the relationship between the learning of epistemological, structuring or second order concepts, and the historical orientation. If the assumption of History Education is that the apprehension of more elaborated or sophisticated concepts, qualify historical learning, how does this learning contribute to the social action and decisionmaking of individuals? Based on this questioning, we conducted a study, using as sources the minutes, or annals, of the "Jornadas de Educação Histórica", between 2001-2017. We selected and more than 60 texts, considered relevant based on criteria defined for the study, carrying out a panoramic analysis of the different ways used by different scholars to relate the two dimensions we question. We observe that the studies of Historical Education arose from the strong initial influence of English researchers, with centrality of the idea of progression in the learning of epistemological concepts, and gradually moved towards an exchange with other references and concerns, with emphasis on the historical consciousness concept. We found that the forms of appropriation and understanding of the relationships between conceptual learning and temporal orientation were diverse, with emphasis on the still strong presence of the idea of conceptual progression in Portugal. And, in Brazil, the predominance of the idea of forming historical consciousness. Finally, we show that exploring the relationship between conceptual learning and historical orientation is a somewhat neglected issue, but also an open possibility, in studies on historical learning in both countries.
\end{abstract}

Keywords: Historical learning. Guidance. Historical consciousness. Historical Literacy.

\footnotetext{
Estudo realizado no âmbito do Estágio Pós-Doutoral no Programa de Pós-Graduação em História na UNB, sob supervisão do prof. Dr. Estevão Martins Rezende. O presente trabalho foi realizado com apoio do CNPq, Conselho Nacional de Desenvolvimento Científico e Tecnológico - Brasil (processo 158291/2018-2).
} 


\section{Introdução: entre a aprendizagem conceitual e a orientação} histórica

O presente artigo tem como problema central a relação entre aprendizagem conceitual e orientação temporal. Definimos por aprendizagem conceitual o que investigadores ingleses chamam de "ways in which history could be given a more rigorous structure, something that might provide a basis for progression in children's unterstanding history, as opposet to the aggregation of thistorical facts, or the memorizing of accounts"2 (LEE; ASHBY; DICKINSON, 1998, p. 227). Se a Educação Histórica tem por função oferecer uma estrutura mais rigorosa para a progressão do entendimento histórico das crianças, essa estrutura se faz por meio da apreensão de conceitos epistemológicos. Essa compreensão é largamente compartilhada por investigadores alinhados com esses estudos em diversos países, especialmente em Portugal e no Brasil.

Este estudo levantou o questionamento sobre a relação entre a apreensão desses conceitos e a forma como os aprendizes mobilizam tais conceitos na orientação histórica de suas vidas. Em outros termos, se a apreensão de conceitos mais elaborados, ou sofisticados, qualificam a aprendizagem histórica, como essa aprendizagem qualificada contribui para a orientação desses mesmo sujeitos?

A concepção de progressão conceitual pode ser definida como uma aprendizagem gradativa e contínua sobre os significados e usos de determinados conceitos que são centrais para compreensão epistemológica da história, como evidência, inferência, perspectiva, empatia e temporalidade, por exemplo. Já a orientação refere-se às compreensões históricas que os sujeitos formulam e às formas através das quais essas compreensões se tornam referências para a formulação de visões de mundo e opiniões que contribuem para a construção de identidades, a tomada de decisões e o agir no mundo com vistas ao futuro.

No Brasil, várias pesquisas apontam para a existência de duas tradições internacionais consolidadas e influentes nos estudos e reflexões teóricas sobre

\footnotetext{
2 "Maneiras através das quais a história poderia gerar uma estrutura mais rigorosa, algo que poderia fornecer uma base para a progressão da compreensão histórica das crianças, em oposição à agregação de fatos históricos, ou à memorização de relatos". (LEE; ASHBY; DICKINSON, 1998, p. 227, tradução nossa)
} 
a aprendizagem histórica (ALVES, 2013; FREITAS, 2014; GERMINARI, 2011; SCHMIDT; URBAN, 2018), que se tornaram as principais influências para as investigações da Educação Histórica. Primeiramente, os estudos realizados na Inglaterra, nos anos 1960-1970, que depois se difundiram por diversos países, originaram-se de uma preocupação com a efetividade do ensino de História. Seu intuito era analisar as possibilidades de crianças e jovens aprenderem a desenvolver raciocínios e reflexões sobre a natureza do conhecimento histórico, entendendo a história como constructo humano, produto de investigações e reflexões, que não se trataria do passado em si (LEE, 2006).

Essa abordagem tem um olhar epistemológico, por priorizar os conteúdos estruturantes do conhecimento e as ideias-chave que tornam a história possível. Essas ideias não se apresentam como um conjunto de informações sobre os feitos humanos no tempo, mas como formas específicas de interpretação e representação desse passado, mediante o uso de raciocínios e métodos de investigação e análise qualificados por critérios científicos (BARCA, 2001a).

A análise desses investigadores se focou nas formas através das quais as crianças e jovens extraem conclusões das fontes e os raciocínios mobilizados para chegar a tais conclusões, analisando a cognição tanto do ponto de vista das noções epistemológicas, os chamados conceitos de segunda ordem, quanto das conclusões específicas sobre as experiências históricas em análise, ou os conceitos substantivos (ASHBY, 2003; LEE, 2006).

A outra corrente a que fizemos referência originou-se na Alemanha, nos anos 1970. Esses estudos abordam os conceitos de consciência histórica, narrativa histórica e pensamento histórico, sendo que o debate está centralizado nas formas como o conhecimento histórico circula, é apropriado e produz efeitos na vida social, sendo a aprendizagem histórica um dos eixos centrais dessa preocupação (RÜSEN, 2012).

A aprendizagem conceitual centraliza o debate na Inglaterra, pois considera-se que a progressão na aprendizagem dos conceitos estruturantes consiste em um ganho efetivo e uma contribuição central do ensino de história para a vida social (LEE; ASHBY; DICKINSON, 1996). Já na Alemanha, o debate relevante centra-se na questão da orientação histórica, que seria o produto final 
das disputas sociais em torno do passado, assim como das relações de ensinoaprendizagem da história (VON BORRIES, 2009).

A proposta de nossa investigação consistiu em explicitar como, nos estudos da Educação Histórica em Portugal e no Brasil, tem sido complexa a apropriação dessas duas influências teórico-metodológicas, especialmente quando se trata de conceituar a aprendizagem histórica e definir objetivos de ensino. Num olhar inicial, há certa coincidência nessas concepções e formulações, de vertente alemã e inglesa, pois ambas apontam para ganhos qualitativos da vida em sociedade derivados da aprendizagem histórica. Entretanto, entendemos que há divergências na forma como as questões são colocadas pelos teóricos e que há necessidade de se analisar empiricamente a coincidência ou não dos pressupostos teóricos com seus resultados efetivos.

Em Portugal, as pesquisas sobre aprendizagem, inspiradas nos estudos ingleses, começaram a ser desenvolvidas no final da década de 1990, especialmente após a difusão das pesquisas de Isabel Barca, professora da Universidade do Minho, que realizou seu doutorado sob orientação de Peter Lee, na Inglaterra. Poucos anos depois, mais precisamente a partir de 2003, Barca difundiu seus estudos no Brasil, por intermédio de pesquisadoras da Universidade Federal do Paraná. Desde então, nos dois países, o termo Educação Histórica tem sido utilizado para denominar os estudos realizados por esses grupos.

As Jornadas de Educação Histórica, evento que congrega os estudiosos alinhados com essas preocupações e metodologias de pesquisa, surgiram no ano 2000, inicialmente como um seminário interno do grupo de pesquisas da professora Isabel Barca, na Universidade do Minho e com a presença de alguns convidados ingleses. Com o decorrer do tempo, o evento foi se expandindo. Sendo que, a partir de 2006, quando foi sediado pela Universidade Federal do Paraná, o evento ganhou caráter binacional e começou a tomar proporções maiores.

Cabe ressaltar que os estudos e debates da Educação Histórica não se restringem a Portugal e Brasil, nem à Universidade do Minho e à UFPR, sendo que há investigadores e grupos de pesquisas em várias localidades aportando 
questões e reflexões para esse campo investigativo. Entretanto, reforçamos que o presente estudo se focou nas publicações das Jornadas de Educação Histórica, por isso haverá prevalência de menções aos trabalhos realizados em Curitiba e Braga, em virtude da grande adesão dos pesquisadores dessas instituições ao evento em análise.

Não pretendemos aqui resgatar um histórico detalhado das Jornadas. Mas cabe ressaltar que a participação dos brasileiros, a partir de 2005, deu outros contornos aos debates na área, especialmente por uma preocupação recorrente dos investigadores em responder às demandas práticas do trabalho educacional, e também da preocupação com a função social do conhecimento histórico, um elemento desde há muito presente nos estudos da área do Ensino de História no Brasil.

Nesse redirecionamento dos estudos da Educação Histórica, da influência inicial dos pesquisadores ingleses para um intercâmbio mais aberto com outras referências e preocupações, o que ganhou destaque foi a presença dos estudos alemães já mencionados, especialmente a preocupação com o conceito de Consciência Histórica de Jörn Rüsen (2001). Esse conceito, que relaciona aprendizagem histórica e vida prática, se torna o elemento unificador de muitos estudos, ainda que com apropriações variadas e às vezes imprecisas.

A presença do conceito de consciência histórica nos trabalhos apresentados nas Jornadas de Educação Histórica e nos demais estudos da área, especialmente a partir de 2006, faz com que seja cada vez mais relevante a preocupação com a unificação das duas dimensões do conhecimento histórico que assinalamos acima: a preocupação com os conceitos estruturantes da investigação e reflexão histórica e a preocupação com as finalidades sociais, políticas e culturais dos produtos desse conhecimento.

O estudo que desenvolvemos consistiu na busca por compreender quais as formas utilizadas por estes investigadores brasileiros e portugueses para lidar com a relação entre a aprendizagem conceitual e a orientação histórica. Nosso intento, a princípio, é observar de que formas diversos investigadores se apropriaram e lidaram com a problemática assinalada e, ainda, se é possível traçar um panorama sobre a importância da aprendizagem conceitual para a 
orientação temporal ou, se, pelo contrário, a questão está em aberto e ainda há caminhos de investigação a serem desenvolvidos.

Como opção metodológica, definimos como objeto de análise a produção acadêmica da Educação Histórica, no Brasil e em Portugal. O corpus documental foi delimitado em torno das atas, ou anais, das Jornadas de Educação Histórica. Optamos por definir a periodicidade de análise entre 2001-2017, em virtude do volume das produções e tempo utilizado para dar conta do levantamento, leitura e análise do material. Além do grande volume de textos publicados no corpus inicial, a pesquisa também agregou alguns outros textos, publicados sob a forma de livros ou artigos em periódicos científicos, que contribuíram para aprofundar a análise.

O presente artigo subdivide-se em quatro tópicos. No primeiro, descrevemos o percurso metodológico da investigação, com a crítica das fontes e as justificativas em torno dos encaminhamentos definidos ao longo do estudo. No segundo, avaliamos como a Educação Histórica, em Portugal, deu ênfase à questão da aprendizagem conceitual. Já no terceiro tópico, demonstramos que a questão da orientação temporal se configurou como foco central da Educação Histórica no Brasil. Por fim, concluímos esse trabalho apontando para lacunas e caminhos de investigação em aberto nas reflexões sobre ensino e aprendizagem da história.

Nosso intento, com este trabalho, é colaborar para o alargamento das investigações sobre as formas, funções e significados da história como componente da cultura escolar e da formação humana. Apesar de atentar-se à dimensão pragmática e normativa do ensino como pontos cruciais dessa reflexão, não buscamos oferecer respostas conclusivas ou receitas, apenas atentar para o fato da imbricação crucial entre o que os ingleses chamam de progressão do pensamento histórico e o que os alemães chamam de formação da consciência histórica. 
Como já assinalamos, o arcabouço documental dessa investigação consistiu basicamente nos textos publicados nas atas, ou anais, das Jornadas de Educação Histórica. Porém, no decorrer do percurso, incluímos algumas publicações de artigos em periódicos e capítulos de livros, que consideramos pertinentes para acompanhar o avanço dos debates na área. Para isso, realizamos uma análise diacrônica, visando observar o avanço desse debate ao longo dos anos.

A princípio, não tivemos acesso aos registros dos eventos realizados em 2008, 2009 e 2014, pois não encontramos a documentação de alguns desses eventos, mesmo buscando os arquivos junto a seus organizadores. Já em relação às Jornadas de 2015, só parte dos trabalhos apresentados foi publicada. Mesmo com esses desfalques, o volume de textos foi grande, e a possibilidade de responder aos questionamentos da pesquisa foi efetivada.

Entendemos que as Jornadas possibilitam uma visão panorâmica, permitindo observar como determinadas problemáticas e questões são abordadas pelos diversos estudos e debates. Nossa análise também levou em conta outras publicações, especialmente as que buscam definir a área, seus limites e especificidades, que ajudaram a orientar nosso olhar analítico e consolidar nossos pontos de vista sobre a produção divulgada nos eventos. Também analisamos algumas teses e dissertações, mas de forma pontual, observando problemáticas bem específicas, pois entendemos que as publicações no evento já trazem os resultados consolidados desses estudos e permitem fazer um balanço sobre as tendências e debates na área.

Como os eventos científicos são abrangentes, ainda que com foco numa área específica, geralmente o volume de trabalhos apresentados e recebidos não contempla, em seu todo, apenas produções estritamente ligadas aos objetivos e referenciais da área. Além disso, há trabalhos de distintos níveis de elaboração e amadurecimento. Nesse sentido, após uma primeira leitura de todos os textos publicados nas fontes, foi necessário estabelecer critérios de classificação das obras, de forma a selecionar especificamente os textos que contribuíram com nossa análise (Quadro 1). 
Quadro 1 - Classificação dos textos por enfoque e estágio da pesquisa.

\section{Classificação dos textos em relação ao domínio teórico-metodológico}

Tipo A: Tratam de questões paralelas ou derivadas (currículos, manuais, patrimônio, formação de professores, práticas, recursos, história do ensino, outras), sem identificar-se com a terminologia, os métodos ou os referenciais específicos da Educação Histórica.

Tipo B: Tratam de questões paralelas ou derivadas (currículos, manuais, patrimônio, formação de professores, práticas, recursos, história do ensino, outras), mas fazem um esforço específico para propor problemas e também utilizar terminologia e referenciais específicos da Educação Histórica.

Tipo C: Trabalhos que podem ser identificados especificamente como estudos de Educação Histórica, subdivididos em três tipos:

C1 - Estudos de reflexão teórica, que fazem sínteses ou desenvolvem temas específicos, mas sem apresentarem resultados de investigações empíricas específicas.

C2 - Estudos vinculados estritamente à influência inglesa, com foco no estudo da aprendizagem histórica, subdivididos em:

C2a - Investigam a progressão das ideias de segunda ordem.

c2b - Investigam ideias prévias, apreensão e ou progressão em conceitos substantivos.

C2C - Investigam tanto conceitos substantivos quanto de segunda ordem.

C3 - Estudos específicos de consciência histórica, vinculados à influência alemã, subdivididos em dois tipos:

C3a - Estudos de memória histórica.

c3b - Estudos de consciência histórica.

\section{Classificação em relação ao estágio da pesquisa ou tipo de reflexão:}

N1: Textos que apresentam ideias gerais, reflexões teóricas ou relatos de experiência superficiais, geralmente apresentados por pesquisadores em formação inicial;

N2: Textos que apresentam reflexões teóricas mais elaboradas, mas com resultados de estudos parciais ou em desenvolvimento.

N3: Estudos que apresentam resultados de investigações em fase de conclusão ou concluídas, com reflexões teóricas amadurecidas e contribuições efetivas ao avanço do conhecimento na área.

Fonte: Elaborado pelo Autor, 2020.

A classificação dos trabalhos analisados pode ser verificada no quadro 1. Dentro dessa classificação, nossa opção foi por analisar somente os textos do tipo C1, C2a e C2c, pois são os que abordam especificamente a problemática da aprendizagem conceitual, com foco nos conceitos de segunda ordem, ou 
estruturantes. É importante esclarecer que os estudos tipo C3 têm uma preocupação específica com a presença de determinados conteúdos históricos na memória dos sujeitos (C3a), ou com a efetividade desses conteúdos como fontes de orientação histórica (C3b). Mas não possuem uma preocupação em relacionar essas memórias ou essa orientação aos conceitos estruturantes, ou de segunda ordem.

É importante destacar, ainda, que esse tipo de trabalho (C3a e C3b), ao longo do tempo, foi se tornando bem mais presente, especialmente entre os pesquisadores brasileiros, revelando uma mudança de foco da aprendizagem histórica para uma preocupação com a presença de determinados conteúdos nas ideias e nas práticas sociais dos indivíduos, revelando a grande influência do conceito de consciência histórica na área, especialmente no Brasil.

Já em relação ao estágio da pesquisa, optamos por analisar os textos classificados como N2 e N3, uma vez que os textos N1, em geral, não possuem reflexões e dados em volume suficiente para serem entendidos como representativos. A partir dessa seleção, foi possível restringir o número de estudos analisados, possibilitando uma maior precisão na investigação. Utilizamos somente textos produzidos por investigadores brasileiros e portugueses, em função do nosso recorte de pesquisa.

Assim, os textos analisados foram os tipos C1, C2a e C2b, desde que estivessem classificados nos estágios N2 e N3, perfilando assim a seguinte quantidade de textos analisados.

Quadro 2 - Quantitativo de textos publicados e textos analisados

\begin{tabular}{|c|c|c|}
\hline $\begin{array}{c}\text { Ano das } \\
\text { Jornadas }\end{array}$ & $\begin{array}{l}\text { Total de textos publicados } \\
\text { nos anais do evento }\end{array}$ & $\begin{array}{l}\text { Quantitativo de } \\
\text { textos analisados }\end{array}$ \\
\hline 2000 & 7 & 2 \\
\hline 2002 & 7 & 2 \\
\hline 2003 & 10 & 3 \\
\hline 2004 & 13 & 2 \\
\hline 2005 & 10 & 6 \\
\hline 2006 & 28 & 5 \\
\hline 2007 & 24 & 7 \\
\hline 2010 & 17 & 7 \\
\hline 2011 & 40 & 6 \\
\hline 2012 & 91 & 7 \\
\hline 2013 & 111 & 4 \\
\hline 2015 & 14 & 1 \\
\hline 2016 & 47 & 4 \\
\hline
\end{tabular}




\begin{tabular}{|c|c|c|}
\hline 2017 & 56 & 2 \\
\hline Total & 475 & 58 \\
\hline
\end{tabular}

Fonte: Elaborado pelo Autor, 2020.

O quadro 2 traz algumas informações que precisam ser ponderadas. Primeiramente, nota-se o baixo número de textos analisados, em relação ao número de textos publicados. Mas a opção metodológica consistiu justamente em tentar extrair, do conjunto das produções difundidas nesses eventos, apenas aqueles trabalhos mais alinhados às preocupações de pesquisa dentro da problemática que levantamos.

Os dados do quadro também revelam o crescimento exponencial do evento ao longo dos anos e uma queda vertiginosa do interesse pela questão da aprendizagem dos conceitos de segunda ordem, especialmente nos anos recentes. Cabe destacar, ainda, que o ano de 2013 foi o que recebeu o maior número de participantes. Mas foi quando o evento teve sua sede em Barcelona, na Espanha, que atraiu um número exponencial de participantes de países hispano-falantes, o que explica a distorção entre o grande número de trabalhos publicados e/ou pequeno número de trabalhos analisados.

Quanto ao ano de 2015, as atas às quais tivemos acesso consistiram num registro do evento realizado em Portugal, com um número bem restrito de trabalhos apresentados e publicados, sendo que a maioria dos apresentados fizeram parte das jornadas realizadas em Cuiabá, uma vez que naquele ano o evento se dividiu em duas sedes, mas não houve publicação dos anais da edição brasileira.

Outro dado relevante consiste no fato de que nas atas das Jornadas de 2017 houve baixa adesão dos participantes no envio de textos para publicação. Observamos, então, que a maioria do que foi publicado se tratou basicamente de trabalhos em fase inicial de estudos, sendo classificados no estágio N1, além de uma grande dispersão temática, que revela certo deslocamento dos interesses de investigadores da área, especialmente no Brasil.

Feitas essas anotações em relação aos dados do quadro, enfatizamos que foram 58 textos analisados, que perfazem aproximadamente 13\% do total presente nas atas. Como já afirmamos, além desse volume de trabalhos extraídos nessa documentação, analisamos outros textos, publicados em livros 
e periódicos, além de algumas teses e dissertações. Esse arcabouço documental que levantamos foi relevante e suficiente para conduzir nosso estudo, que inicialmente havia sido proposto a partir dos seguintes questionamentos:

1. Com relação ao período inicial, antes de 2006, quando os debates sobre consciência histórica ainda não haviam entrado em cena, quais conceitos e reflexões identificavam uma preocupação com os impactos sociais da aprendizagem no sentido de uma orientação histórica?

2. Havia uma preocupação inicial com a ideia de formação histórica, ou seja, com a finalidade específica da aprendizagem histórica? Que ideia de formação era essa?

3. Com relação ao segundo período, pós 2006, a presença dos referenciais teóricos alemães trouxe quais mudanças na forma de abordar essas questões sobre a orientação e a formação histórica?

4. No segundo período, como os estudos relacionaram a questão da aprendizagem dos conceitos epistemológicos aos conceitos de narrativa e consciência histórica?

5. É possível identificar, nos estudos empíricos, evidências de que a progressão conceitual aponte para determinadas formas de orientação histórica? Essa relação é interpretada de que forma pelos investigadores? E, caso não seja abordada, quais conclusões podemos tirar desses dados?

6. As formas de apropriação dos conceitos de narrativa e consciência histórica nos trabalhos da Educação Histórica evidenciam articulações teóricas coerentes e compatíveis ou se constituem como sobreposição ou paralelismo de conceitos não necessariamente convergentes?

7. É possível identificar diferenças de abordagem dos conceitos de consciência histórica e narrativa histórica entre os trabalhos realizados pelos pesquisadores brasileiros e os trabalhos dos pesquisadores portugueses? Se há essas diferenças, quais elementos permitem compreendê-las?

Das sete questões elencadas acima, optamos por descartar a questão 5, pois exigia uma reanálise dos dados empíricos publicados por diferentes 
pesquisadores sobre a aprendizagem histórica dos estudantes, no sentido de verificar se a questão da orientação histórica estava presente nesses trabalhos, ainda que não explorada. Abdicamos de respondê-la pelo fato do material disponível não fornecer elementos para análise, uma vez que a maioria dos estudos empíricos publicados nas Jornadas traz resultados sem apresentar todo o material empírico analisado e, mesmo quando apresenta esse material, tratase de amostras pequenas, apenas exemplos de excertos das falas e textos dos alunos, ou tabelas, classificando suas ideias.

Quanto às outras seis questões, optamos por mantê-las, mas muitas vezes se entrecruzavam e diziam respeito aos usos de determinados conceitos, como narrativa e consciência histórica, assim como a adequação desses usos e a diferença de apropriações entre os estudiosos dos dois países analisados. Sendo assim, optamos por fazer uma apresentação dos resultados em dois blocos, um para cada país, ao invés de tentar responder cada questão em separado.

Na sequência, a partir dos resultados de nosso estudo, sintetizamos os debates da Educação Histórica subdividindo-a conforme os países. Primeiramente, apresentaremos os resultados da análise sobre os estudos portugueses, entre os quais observamos uma tendência, muito evidente, na qual predomina uma visão pragmática dos conceitos de segunda ordem e da ideia de aprendizagem conceitual. A prioridade é o estabelecimento de parâmetros, níveis e metas de aprendizagem, sendo que a ideia de consciência histórica e, por consequência, a questão da orientação, tornam-se preocupações recorrentes, mas não implicam um abandono das questões preexistentes em relação à aprendizagem conceitual.

\section{A questão da articulação entre aprendizagem conceitual e orientação temporal nos trabalhos da Educação Histórica em Portugal}

Até a edição de 2004, as Jornadas de Educação Histórica tiveram por característica tratar-se de um evento pequeno e restrito, composto basicamente por membros do grupo de pesquisa liderado pela professora Isabel Barca, na universidade do Minho, e com a participação de pesquisadores convidados, 
especialmente ingleses. Já em 2005, iniciou-se uma parceria com pesquisadores brasileiros, o que deu início a esse caráter binacional do evento, que viria a se ampliar e consolidar nos anos seguintes.

Entretanto, a princípio, fizemos um recorte temporal no período de 2000 2005, entendendo que nesse momento há características específicas nos estudos da Educação Histórica em Portugal. Essa especificidade consiste no fato de haver a centralidade do debate em torno da aprendizagem conceitual, com uma forte preocupação com a progressão da aprendizagem dos alunos em torno dos conceitos de segunda ordem, especialmente pela influência dos estudos advindos da Inglaterra.

Num momento inicial, não havia uma ideia de formação histórica consolidada, sendo que o foco estava na defesa da progressão da aprendizagem dos conceitos de segunda ordem, como um objetivo em si para o ensino. Nesse contexto, Barca aponta para concepção de "transformação do senso comum em pensamento científico" (BARCA, 2001b, p. 7), sinalizando para um ensino de história que privilegia os conceitos epistemológicos.

Em um trabalho sobre múltiplas perspectivas em história, Barca define:

Não será útil para os jovens considerar que qualquer resposta sobre o passado é apenas uma questão de opinião pessoal ou de ponto de vista. Eles precisam exercitar um pensamento crítico, de aprender a selecionar respostas mais adequadas sobre o real, passado e presente. (BARCA, 2001b, p. 30)

A professora evidencia ainda que o foco da Educação Histórica deve ser o desenvolvimento de competências de organização e seleção da informação "tão necessárias num mundo de informação plural e contraditória” (BARCA, 2001b, p. 39).

Nessas primeiras incursões de Isabel Barca sobre as questões da orientação histórica, evidencia-se certa confiança na instrumentalização dos alunos, no sentido do domínio de conceitos epistemológicos, o que constituiria uma ampliação no aparato de ferramentas dos estudantes para adotarem uma postura mais crítica diante dos desafios da vida em sociedade, como a multiplicidade de informações. 
Esse entendimento permaneceu influente nos anos seguintes, aprofundando-se a visão otimista sobre os potenciais da aprendizagem conceitual. Marília Gago afirma como um objetivo da Educação Histórica "desenvolver nos alunos competências que lhes permitam perscrutar o mundo com seus próprios olhos para que possam percorrer o caminho munidos de ferramentas que os auxiliem a compreender a sociedade que os rodeia" (GAGO, 2006, p. 55).

Em um texto sobre a Aula Oficina, Isabel Barca reforça a concepção do desenvolvimento de competências cognitivas para progredir no domínio dessas ferramentas de investigação e reflexão sobre a história, ou a "compreensão disciplinar":

A implementação do currículo de História em Inglaterra constitui um exemplo de consistência na aplicação desta nova filosofia (DEE, 1999 apud BARCA, 2004, p. 135).

Os grandes alvos da aprendizagem (attainment targets) referemse ao desenvolvimento de competências - no domínio de cronologia, conhecimento e compreensão dos temas em âmbito e profundidade, interpretações da História, pesquisa histórica (interpretação de fontes) e comunicação - e são apresentados numa progressão de complexidade ao longo da escolaridade obrigatória. (BARCA, 2004, p. 135-136)

Esse foco nas ferramentas conceituais, como elementos capazes de conduzir crianças e jovens a formas mais avançadas de viver em sociedade, não explicita exatamente do que se trata essa melhor convivência. Entretanto, apesar de não investigarem ou evidenciarem uma relação explícita entre aprendizagem e orientação, uma vez que esses estudos não exploram diretamente essa questão, em algumas argumentações ao longo dos textos é possível visualizar o que compreendem por uma melhor orientação.

Barca (2006, p. 21), por exemplo, fala em "Educação Histórica para uma sociedade aberta, plural e tolerante". Regina Parente (2009) argumenta sobre a necessidade do desenvolvimento de capacidades intelectuais, valores éticos, morais e humanistas, através dos quais se pretende configurar uma consciência histórica. Clarissa Fonseca (2009) defende que o conceito de empatia histórica contribui para desenvolver atitudes de respeito, tolerância e compreensão da diversidade. 
Assim, observamos que, inicialmente, os trabalhos centravam-se na ideia de progressão conceitual. Em alguns casos, o foco era nos chamados "conceitos substantivos”. Mas há, nesses casos, uma imprecisão na definição do que seriam esses conceitos, muitas vezes confundidos com conceitos genéricos, como liberdade, cidadania, religião e sociedade, outras, com conceitos propriamente históricos, como Renascimento. Mas predomina a preocupação com a aprendizagem dos "conceitos de segunda ordem", dentre os quais “multiperspectiva”, mudança, evidência, empatia, objetividade, variância, narrativa e significância histórica.

Essa identificação inicial dos portugueses com a ideia de progressão na aprendizagem conceitual, aos poucos vai ganhando novos contornos com a ascensão da preocupação com a ideia de consciência histórica, especialmente a partir de 2006, ainda que a definição precisa do conceito e sua utilidade para os estudos da área não estivessem bem delimitadas. O trecho a seguir é ilustrativo dessa nova tendência.

A preocupação em reflectir sobre os usos do saber histórico: será que ele se constitui como um conjunto de curiosidades interessantes, mas que para nada servem ou deverá ter implicações para a vida quotidiana? A reflexão sobre os usos dos significados atribuídos à História (idéias substantivas e de segunda ordem) afigura-se urgente para justificar o papel da História no currículo e contribuir para um ensino que promova uma consciência histórica consentânea com as exigências de desenvolvimento e cidadania na sociedade actual. (BARCA, 2007, p. 26-27)

Na citação, notamos a mescla que a investigadora portuguesa faz entre as preocupações com a aprendizagem conceitual e a inserção da questão da consciência histórica nos debates. Cabe ressaltar que Barca reconhece a existência de uma concepção de consciência histórica, que revela as formas através das quais os sujeitos se apropriam do passado na formulação de suas identidades e orientação do seu agir. Entretanto, centra-se ainda na contribuição da Educação Histórica, que é lidar com as ideias substantivas e de segunda ordem dos estudantes. 
Há, nessa apropriação do conceito de consciência histórica, uma especificidade. Isso porque nos trabalhos de Rüsen (2001), a consciência histórica é caracterizada como um conjunto, ou suma, de operações mentais a partir das quais os sujeitos lidam com a experiência histórica, interpretando-a e embasando suas orientações temporais. Entretanto, para Barca, a consciência histórica se revela mais como uma visão elaborada da temporalidade, consubstanciada por elementos de racionalidade próprios da ciência histórica.

Barca chega a usar a expressão 'ter consciência histórica', argumentando que essa definição tem a ver com a aquisição de um certo sentido "do que é história como disciplina acadêmica, dominar determinadas competências históricas, construir uma narrativa da condição humana” (BARCA, 2008, p. 48). Essa concepção diverge da teoria de Rüsen, para quem a consciência histórica é uma forma de raciocínio elementar, a partir da qual os indivíduos e as sociedades lidam com as experiências temporais, podendo ocorrer inclusive em sociedades em que não haja o conceito de história acadêmica (KÖRBER, 2016).

Não nos aprofundaremos nessas apropriações do conceito, pois já realizamos essa tarefa em outro estudo ${ }^{3}$, no qual demonstramos como, ao longo dos anos, o entendimento de consciência histórica apresentado por Barca e por outros pesquisadores portugueses foi se redefinindo. O que ressaltamos é que a influência da ideia de progressão conceitual, assim como a centralidade dos conceitos epistemológicos na formação do pensamento histórico, são imperativos nas produções de Isabel Barca e, por conseguinte, nos trabalhos dos demais investigadores portugueses da Educação Histórica.

Nesse contexto, é importante destacar projeto "HICON - consciência histórica - Teoria e Prática”. Barca (2014), informa que o projeto surgiu em 2003, apesar das menções a ele terem sido feitas apenas nas jornadas de 2005, e finalizou-se em 2011. O projeto partiu da questão "que consciência histórica revelam os jovens em situação de escolaridade" (BARCA, 2014, p. 87). Além de Portugal, esse projeto abrangia também investigações no Brasil, em Moçambique e em Cabo Verde. 
Segundo Magalhães (2007), o projeto buscou analisar as ideias dos alunos sobre significância, narrativa, explicação e evidência. Num primeiro olhar, já se observa que, apesar de se relacionarem à consciência histórica, os estudos ainda seguem a tradição de priorizar determinados conceitos estruturantes para observar as ideias dos alunos. Nesse sentido, analisar a consciência histórica não estava relacionado diretamente à orientação histórica, mas à mobilização de determinadas "ideias históricas" pelos alunos.

Nesse contexto, o conceito de narrativa é o mais significativo. Inicialmente, narrativa era um termo que traduzia o termo inglês "account", utilizado para classificar a capacidade dos alunos de reunir fontes e organizá-las em um relato estruturado sobre um conjunto de acontecimentos históricos, analisando-se os níveis de estruturação dos relatos. Com o projeto Hicon, o conceito de narrativa passou a ser entendido como as histórias que expressam a consciência histórica dos indivíduos, muito próximo ao que Rüsen (2010) define como narrativa. Entretanto, ao invés de abordar a narrativa como uma forma de produzir sentido ao mundo, e preocupar-se com as orientações expressas nas narrativas, os estudos portugueses classificam seus níveis de estruturação, os marcos temporais, as personagens centrais, as ideais de mudança e continuidade, entre outros elementos. Ou seja, não se estabelece um foco sobre o conteúdo das narrativas e seus significados, mas sobre níveis de sofisticação das narrativas.

Olga Magalhães (2007, p. 103) tenta articular os conceitos de segunda ordem à ideia de orientação histórica definindo como objetivo do seu estudo compreender "Como é que os alunos portugueses relacionam as suas ideias sobre mudança e significância do passado com a compreensão da sua vida actual e as perspectivas para o futuro?” Entretanto, sua análise sobre as narrativas dos jovens centra a preocupação nos níveis de narrativa, e não exatamente no conteúdo dessas narrativas e nem nos seus significados do ponto de vista da orientação. Magalhães analisa e categoriza as ideias dos alunos em diferentes patamares de conhecimento, identificando as necessidades de desenvolvimento. Nos níveis em que foram categorizadas as ideias relacionadas a uma consciência histórica mais desenvolvida, destaca a necessidade de 
estabelecer marcos temporais, e relacionar estes entre si, definindo as causas e consequências dos acontecimentos.

Barca (2008) entende que a consciência histórica trata de uma orientação temporal sustentada pelo conhecimento da história, distinguindo-se de respostas do senso comum. Aponta, ainda, para o entendimento de que há certas formas de consciência que são mais avançadas, pois envolvem a aquisição de um sentido sobre a história como disciplina acadêmica, o que inclui dominar certas competências historiográficas.

Essa concepção de consciência histórica avançada torna-se, então, o elo entre a aprendizagem conceitual e a orientação temporal. Nesse entendimento, para se orientar de uma forma mais adequada na vida em sociedade, os sujeitos precisam dominar conceitos da operação historiográfica. A partir desse entendimento, Barca (2011) aponta que a Educação Histórica tem um papel no desenvolvimento social, que consiste em possibilitar a progressão do pensamento histórico e promover um quadro coerente do passado, que possibilite uma orientação consistente para a vida dos alunos. Nessa abordagem, ficam abertas algumas questões, pois não há explicitamente uma indicação do que seria consistente do ponto de vista da orientação, nem em relação a que o quadro promovido seria coerente.

Barca fala em "fornecer ferramentas intelectuais indispensáveis à interpretação e à explicação da realidade” (2011, p. 25), assim como:

Aprofundar os níveis de compreensão do passado e do presente a partir de ideias de senso comum, integrando significâncias e critérios metodológicos próprios da História, apresenta-se, pois, como um objetivo central da educação histórica e social, numa problematização aberta à argumentação, e no contexto de uma postura que genuinamente contenha um sentido humano. (BARCA, 2011, p. 25-26)

Fica evidente o entendimento de que há uma contribuição da racionalidade histórica para a vida social, e Barca dá algumas pistas de que contribuição é essa, como a abertura à argumentação e uma postura que indique um "sentido humano". Mas esses objetivos são muito abstratos, pois o foco está em que ensino de história deve buscar uma aprendizagem conceitual. Isso fica ainda mais 
evidente quando a autora, nesse mesmo artigo, define o que considera as competências em História, quais sejam: saber ler fontes (diversas, vários níveis, formatos); confrontar fontes nas suas mensagens, intenções, validades; selecionar fontes, confirmação e refutação de hipóteses; entender o 'nós' e os 'outros' em diferentes tempos e espaços; levantar novas questões, novas hipóteses a investigar.

As competências assinaladas por Barca têm uma relação muito estreita com o fazer historiográfico. Mas a contribuição desse tipo de raciocínio para uma orientação histórica efetiva é vaga, pois o foco se situa sobre a atitude crítica dos indivíduos frente à sociedade e às histórias que circulam socialmente. Em outros termos, não há uma ideia de futuro no seu pensamento, pois no fundo o futuro depende das atitudes do presente, e o ideal é que essas atitudes sejam fundamentadas em determinados critérios de racionalidade.

No texto de Marília Gago (2008) há certa divergência em relação às formulações de Barca pois, junto à questão da orientação histórica, insere os componentes da formação e do respeito às identidades. Todavia, reforça a concepção de que o alargamento da consciência histórica tem relação com o domínio de concepções e procedimentos advindos das investigações científicas em história. Gago afirma que a orientação temporal varia de acordo com as memórias disponíveis e que uma orientação que resulte de uma consciência histórica avançada não consiste somente na memória e na identidade, pois envolve também uma compreensão racional do passado. Percebe-se que Gago corrobora as ideias de Peter Lee (2007), de que a consciência histórica vai além de um sentimento instintivo de identidade, abrangendo uma compreensão da história como disciplina acadêmica bem como das metodologias historiográficas.

Gago (2008) traz à luz uma circunstância na qual a relação entre consciência histórica e identidade torna-se mais nítida. O sentimento de pertencimento a determinado grupo identitário faz com que indivíduos se vejam como protagonistas em eventos históricos pelos quais esse grupo passou, mesmo que não os tenham vivenciado. A consciência histórica é entendida como mediadora no processo de produção de narrativas, facilitando a compreensão do humano do mundo ao seu redor, de si e dos outros. 
De acordo com Gago, ser "historicamente competente” implica numa reelaboração constante das experiências, com base na compreensão do passado, em direção à construção de uma narrativa que resulte em uma orientação temporal. Concluindo, a autora afirma que: "aprender História será aprender-se a si próprio, isto é, ao acentuar-se a dimensão temporal da identidade pessoal há uma tomada de consciência de si e do seu tempo." (GAGO, 2008, p. 57).

Em síntese, ela se aproxima dos sentidos originais dos conceitos de narrativa e consciência histórica, sintetizados pelos trabalhos de Rüsen (2001). Entretanto, não se desloca do ponto central para os portugueses, o estabelecimento de padrões de competências referenciados nas concepções e procedimentos do fazer historiográfico. Esse mesmo raciocínio pode ser encontrado em Ana Catarina Simão que, em seu trabalho, busca "perceber como os alunos aprendem História, que conceitos estruturais, ou de 'segunda ordem' mobilizam na sua construção do conhecimento histórico, como constroem sua consciência histórica, ou seja, como dão sentido à história para si mesmos" (SIMÃO, 2011, p. 108).

Barca (2014), argumenta que a consciência histórica em sua dimensão ontogenética é a que melhor equipa os seres humanos para enfrentar os problemas na atualidade, enquanto o conceito de literacia histórica consiste na formação de competências cognitivas essenciais para a vida na sociedade da informação e de busca de desenvolvimento sustentável. Contudo, sua análise sobre as narrativas de alunos portugueses, que revelam a consciência histórica desses jovens, visa estabelecer aspectos estruturais dessa narrativa, como marcadores cronológicos, marcadores substantivos, mensagem nuclear e identidade nacional. Nesse sentido, não há uma reflexão sobre os horizontes de expectativa desses jovens, ou sobre a orientação histórica refletida nessas narrativas, menos ainda algum tipo de investigação ou reflexão sobre como a aprendizagem conceitual qualificaria essas narrativas no sentido da orientação.

Gago (2011) faz um trabalho parecido, identificando padrões narrativos no pensamento dos alunos, como história cíclica, pedagógica e "erros a evitar", ainda com foco em estruturas das narrativas, sem atentar-se para o que geram em 
relação a expectativas de futuro, nem que tipo de intervenção no sentido da progressão do pensamento histórico as qualificaria.

Os trabalhos de Julia Castro, sobre interculturalidade e consciência histórica (CASTRO, 2008; CASTRO, 2011) também apontam para essa iniciativa de articular o pensamento de Rüsen aos conceitos de segunda ordem, argumentando que os aportes teóricos do historiador alemão abrem a possibilidade de maior sofisticação e robustez do pensamento histórico, numa base multiperspectivada, coerente e objetiva. A abordagem é sobre conceitos de significância, empatia e narrativa, buscando as contribuições desses conceitos à orientação no sentido da convivência social, voltada para o reconhecimento das identidades e de superação dos conflitos culturais.

Entretanto, em ambos os trabalhos, Castro (2008, 2011) realiza investigações centradas em classificar e categorizar as ideias mobilizadas pelos alunos a partir de tarefas específicas, com temáticas pré-definidas, centradas em significância e empatia histórica, no primeiro estudo, e em marcadores temporais das narrativas históricas elaboradas pelos alunos, no segundo.

O que se observa são dois aspectos recorrentes; o primeiro é o de se buscar analisar a consciência histórica dos jovens a partir de determinadas tarefas propostas pelos investigadores, e não das próprias experiências dos sujeitos e de suas protonarrativas. O segundo, que se revela comum nesses trabalhos, é que a relação entre a aprendizagem de conceitos de segunda ordem, como empatia, e a mobilização desses conceitos na vida em sociedade, não é explorada.

Maria Helena Pinto (2011) desenvolve um estudo interessante, ao trabalhar com os patrimônios históricos e lugares de memória. Nesse trabalho, consegue articular o estudo dos conceitos de segunda ordem como o estudo da consciência histórica. Ao estudar o patrimônio histórico e, simultaneamente, o conceito de evidência, explorando formas de enxergar evidências históricas nos patrimônios, articula a consciência histórica a um conceito de segunda ordem. Esse estudo possibilita abordar um elemento de ordem cultural, que se relaciona aos símbolos de pertencimento e de identidade local, ao mesmo tempo em que problematiza a possibilidade de analisá-los como documentos históricos. 
Nessa abordagem, a consciência histórica tem a utilidade de trazer à realidade uma orientação temporal que possa reger a ação intencionalmente pela mediação da memória histórica. A autora afirma que os conteúdos curriculares ganham outro sentido com o ensino a partir das fontes e dos materiais de história local, porque estes se encontram referenciados nas experiências individuais e coletivas dos alunos e professores, na dimensão cultural da comunidade. Pinto (2011) afirma que a apropriação do conceito de evidência histórica pelos alunos é fundamental, ressaltando que não se pode esquecer o estudo e a sensibilização para o patrimônio e a sua função na consolidação e perpetuação de identidades, pois tudo isso leva à construção de pensamento e consciência históricos.

$\mathrm{Na}$ esteira dessa tentativa de articular preceitos baseados na efetividade da aprendizagem conceitual para a orientação temporal, a partir de uma ideia de "consciência histórica sofisticada”, algumas dessas investigadoras portuguesas participaram da elaboração das Metas de Aprendizagem (DGIDC, 2010) na área de História, um documento curricular oficial do Ministério da Educação em Portugal, que tomou por base a concepção de progressão conceitual para estabelecer diretrizes nacionais para o ensino de História.

Os trabalhos sobre as metas de aprendizagem apresentados nas XI Jornadas (DIAS; SOLÉ, 2011; SIMÃO; BARCA, 2011), revelam a convergência dos estudos em Portugal para uma ideia central, a de que a contribuição dos estudos da Educação Histórica para o ensino consistiam em estabelecer níveis de domínio de determinados conteúdos estruturantes do pensamento histórico, no sentido de fomentar a consciência histórica mediante o domínio das operações epistemológicas. É o que chamou-se de um "pensamento histórico de qualidade", o que significa a construção de uma "consciência histórica mais sofisticada e abrangente", relacionando fatos e contexto com o desenvolvimento de capacidades de "analisar, interpretar e fundamentar historicamente" (SIMÃO; BARCA, 2011, p. 65).

Entretanto, é importante ressaltar que essa confiança no potencial da aprendizagem conceitual em fornecer uma orientação histórica adequada aos estudantes, vinha acompanhada de alguns valores considerados fundamentais 
para a vida em sociedade, como "interpretar o mundo atual de forma crítica e fundamentada, não aceitando, sem reflexão, a hegemonia da cultura de massas num mundo globalizado mas com extremas desigualdades de oportunidades" (SIMÃO; BARCA, 2011, p. 65). Envolvendo também uma concepção já mais bem definida de formação histórica:

Formação e consolidação de uma consciência social aberta, democrática e participativa, através da contextualização de fenômenos complexos e de um treino para lidar com as diferenças e semelhanças, as mudanças e as permanências, a cooperação e a conflitualidade, as situações de crise ou estagnação e de progresso. (SIMÃO; BARCA, 2011, p. 67)

Cabe ressaltar que as citações de trabalhos que fizemos até aqui limitamse ao período de 2005-2011. Entretanto, as preocupações e abordagens se mantiveram nos anos subsequentes, quando as Jornadas se popularizaram ainda mais, incluindo a presença de centenas de participantes, mas sem incrementar novos conceitos ou reflexões sobre as questões em debates, das relações entre aprendizagem conceitual e orientação temporal.

Para corroborar com essa afirmação, podemos utilizar a introdução às jornadas de 2015, realizadas em Portugal, texto no qual Alves e Barca reafirmam que em Educação Histórica: "Busca-se compreender como os alunos constroem o seu pensamento histórico, que não é feito apenas de conhecimento substantivo, mas engloba também, necessariamente, uma certa estrutura conceptual no entendimento do passado", afirmando ainda que "Saber História implica saber narrar (descreve e explicar) e argumentar sobre situações humanas passadas, à luz da evidência disponível” (BARCA; ALVES, 2016, p. 6).

Enfim, as palavras de Alves e Barca endossam o que afirmamos antes, da tendência em se considerar que a aprendizagem conceitual da história é o princípio que deve guiar a consciência histórica dos jovens estudantes. Em outros termos, a progressão no domínio dos conceitos epistemológicos é condição sine qua non da qualificação da aprendizagem e da orientação histórica dos indivíduos.

Já no Brasil, as reflexões em torno dos conceitos de segunda ordem, como veremos adiante, não chegaram a ser uma prioridade. O que se nota, no caso 
brasileiro, é uma preocupação central com a ideia de orientação histórica, que já era latente desde as primeiras incursões dos investigadores brasileiros pela Educação Histórica, e que define um caráter particular para os estudos da área no Brasil, afastando-se do que havia sido preconizado pelos estudos ingleses. Esse é o tema do próximo tópico.

\section{A Educação Histórica no Brasil: cultura, sentidos sociais e orientação}

Como visto, as primeiras participações brasileiras nas Jornadas de Educação Histórica ocorreram em 2005, mas a parceria entre investigadores do grupo brasileiro e do grupo português data de 2003, com a participação de Isabel Barca em um seminário na UFPR. Essa proximidade foi profícua na difusão, no Brasil, dos conceitos e reflexões presentes nos estudos portugueses, contribuindo com diversas produções acadêmicas, como dissertações de mestrado, teses de doutorado e projetos de pesquisa, com presença significativa em alguns programas de pós-graduação em História e Educação.

Entretanto, apesar do grande volume de produções brasileiras nos eventos realizados desde então, esta produção é mais tímida no que diz respeito à relação entre aprendizagem conceitual e orientação temporal. Isso se explica por uma série de características que identificaremos ao longo desta reflexão, mas, a princípio, podemos afirmar que a especificidade da Educação Histórica no Brasil é um conjunto de preocupações bem distinto do que circulou entre os investigadores portugueses.

Para corroborar essa constatação, começamos observando como a participação brasileira nas jornadas de 2005, que consistiu em dois trabalhos publicados, já evidencia como a noção de aprendizagem conceitual aparece em segundo plano. Nesses estudos, são apresentadas preocupações com a transformação de conteúdos relevantes em "habilidades sociais para as novas gerações" (SCHMIDT; GARCIA, 2009, p. 30), assim como uma preocupação com a aprendizagem de determinados conceitos pelos alunos, mais relacionados à orientação que ao domínio de procedimentos historiográficos, como no caso de um projeto sobre o conceito de cidadania (THEOBALD, 2009). 
Nas edições seguintes, outra característica dos estudos brasileiros que se destacou foi a preocupação com a consciência histórica, principalmente com as identidades dos estudantes, a partir da definição de determinados temas históricos considerados relevantes e da busca por compreender como os jovens lidam com essas temáticas. O trabalho de Lindamir Fernandes (2007) propõe um estudo sobre significância histórica, mas centrado na história da "conquista dos direitos da mulher" e preocupado com as três dimensões da consciência histórica: experiência, interpretação e orientação.

Maria Auxiliadora Schmidt e Tânia Braga Garcia (2007) apresentam experiências pedagógicas no trabalho com o resgate de memórias familiares a partir de objetos guardados nas casas das crianças, articulando essas memórias a contexto históricos e sociais mais amplos. Esse trabalho, segundo as autoras, possibilitava: formar uma consciência histórica "crítico-genética"; desenvolver empatia histórica; produzir narrativas mais complexas; desenvolver conceitos a partir dos conhecimentos prévios.

Para além dessas possibilidades indicadas pelas autoras, Schmidt e Garcia (2009) apontam ainda que a intenção da metodologia empregada é superar o que chamam de "sequestro da cognição", pois esse sequestro impossibilita que os sujeitos acessem outras possibilidades de entendimento do tempo histórico e restringem a formação da consciência histórica. Assim, o trabalho direciona-se à construção do conhecimento derivada dessa metodologia específica, de lidar com os arquivos familiares, e não uma preocupação específica com a progressão no uso dos conceitos de segunda ordem.

Esses primeiros trabalhos analisados, formulados por investigadores brasileiros, já revelam a tendência que seguiria sendo reproduzida nos demais estudos que viriam a ser produzidos. Primeiramente, um uso dos conceitos de segunda ordem de forma tímida, praticamente sem a realização de investigações específicas sobre a progressão da aprendizagem nesses conceitos. Em outro âmbito, um foco nas preocupações com a orientação histórica dos alunos, com destaque para preocupações políticas e sociais que envolvem a realidade dos estudantes. 
Nas VII Jornadas, Schmidt (2008) apresenta um balanço das investigações em Educação Histórica realizadas na UFPR. Neste texto, há uma reiteração do objetivo de formação de uma "consciência histórica crítico-genética" e propõese que:

Confrontando conteúdos encontrados nos livros e manuais com as suas próprias narrativas e com outras encontradas por eles em atividades de investigação, os alunos podem adquirir procedimentos que colaboram para que eles tomem consciência de que o sentido do passado não se encontra na perspectiva somente de permanência e continuidade, mas fundamentalmente de mudança. (SCHMIDT, 2008, p. 119)

Assim, a ideia de orientação para a mudança, ou seja, um princípio transformativo do ensino de História, é relevante para Schmidt, que argumenta ainda que é preciso "levar em conta uma séria reflexão sobre a natureza do conhecimento histórico e seu papel como ferramenta para análise da sociedade e como recurso para a construção da consciência histórica, portanto, como formação para cidadania” (SCHMIDT, 2008, p. 119).

Já o texto de Braga (2008) busca trazer alguns resultados do projeto Recriando Histórias, um trabalho desenvolvido a partir da metodologia de se usar as fontes guardadas em arquivos familiares como materiais para o ensino. Sobre essa metodologia, Braga indica que o intuito é formar a consciência histórica, e tenta articular esse conceito à noção de consciência crítica de Paulo Freire, que propõe "levar os homens à luta contra os obstáculos à humanização" (GARCIA, 2008, p. 133).

Evidencia-se, assim, que nos estudos brasileiros, a ideia central consiste em pensar a consciência histórica como objetivo de formação, no sentido de transmitir valores e sentidos sociais do conhecimento histórico, voltados à transformação, seja para a cidadania ou para a luta contra injustiças. O trabalho de Geyso Germinari (2011) é interessante nesse sentido, pois seu estudo de cognição histórica está centrado na ideia de exclusão social, uma vez que confronta a versão oficial da narrativa histórica fomentada pelas autoridades da cidade de Curitiba com as experiências e narrativas de estudantes sobre a cidade, evidenciando distanciamento entre discursos oficiais e percepções dos jovens sobre a história local. 
O trabalho de Germinari evidencia uma preocupação que se faz presente na maioria das investigações em Educação Histórica no Brasil, que consiste em abarcar o conceito de cultura como aspecto relevante das pesquisas. Em artigo publicado em 2006, Schmidt e Garcia já sinalizavam para essa importância, indicando a influência dos estudos culturais de Raymond Willians, Basil Bernstein e Stuart Hall, que abordam:

[...] temáticas como relações de gênero e ensino, questões de identidade e ensino, exclusão/inclusão e ensino, bem como a especificidade das relações dos sujeitos com o conhecimento escolar, na dimensão da cultura e da sua relação com os processos de escolarização. (SCHMIDT; GARCIA, 2012, p. 16)

Assim, o entendimento é que, ao chegar à escola, crianças e jovens já possuem conhecimentos e percepções de mundo advindos de suas experiências familiares, comunitárias, sociais e que existem substratos de cultura que devem ser fonte de análise e reflexão para o ensino. Nesse sentido, as preocupações de investigação sobre a aprendizagem levam em conta que os jovens não são indivíduos neutros, tábulas rasas, mas sujeitos participantes de universos culturais mais amplos. E também que no interior das escolas se estabelecem relações, não só nas práticas, normas e rotinas dos processos de escolarização, mas também as estabelecidas entre os sujeitos presentes nesse universo.

Cabe ponderar que a preocupação com as chamadas "ideias prévias" dos estudantes também é uma característica importante nos estudos da Educação Histórica em Portugal. Entretanto, a diferença é que, enquanto os portugueses centram-se em explorar ideias prévias sobre determinados "conceitos substantivos" a serem trabalhados nos processos de ensino/aprendizagem, os brasileiros radicalizaram essa proposta a partir dos conceitos de cultura e de consciência histórica. O intuito desses estudos é compreender essas ideias a fundo, suas influências sociais e culturais, assim com sua presença nos processos de escolarização.

O trabalho com o conceito de cultura nesse sentido do enraizamento e das visões de mundo de estudantes e professores, e de sua interferência nos processos de ensino, estabelece novos parâmetros para se pensar a aprendizagem histórica. Ao invés de entender a aprendizagem histórica como 
domínio gradual de conceitos epistemológicos, a questão torna-se a autodescoberta dos estudantes, a compreensão de suas raízes históricas e a crítica às formas como determinadas visões se apresentam, configurando visões distorcidas que formam identidades excludentes.

Outra maneira de abordar o conceito de cultura na aprendizagem histórica, nos estudos brasileiros, se fez presente em trabalhos que utilizaram a concepção de artefatos culturais, analisando como os jovens estudantes lidam com a possibilidade de aprender história a partir das histórias em quadrinhos (Fronza, 2011), de canções (Azambuja, 2011) e de filmes (Souza, 2012). Nesses trabalhos há uma preocupação com o conceito de cultura juvenil, relacionando gostos, valores e identidades dos jovens ao consumo desses produtos culturais, procurando analisar possibilidades de aprendizagem histórica nessa relação.

Esses trabalhos, em certa medida, lidam com a ideia de aprendizagem conceitual, uma vez que, tomando os artefatos culturais como fonte, desafiam a cognição dos estudantes através da busca por compreender como manifestam determinados conceitos estruturantes, como objetividade e verdade (FRONZA, 2011) e multiperspectividade (SOUZA, 2012).

Ainda assim, a preocupação dos estudos brasileiros não é com a progressão da aprendizagem conceitual; por isso mesmo, com a exploração desses "conceitos de segunda ordem", também chamados por esses pesquisadores de categorias epistemológicas, não há uma preocupação geral em observar uma progressão no domínio dessas categorias nem a efetiva utilidade dessas na orientação dos estudantes. Esses estudos buscam observar elementos complicadores na relação, como na investigação de Souza (2014), que aponta para a dificuldade dos alunos em lidar com a ideia de multiperspectividade, revelando raciocínios binários e maniqueístas na análise da história nos filmes. Assim como Fronza, que tenta observar como lidar com a concepção de verdade relaciona-se ao desenvolvimento da intersubjetividade nos jovens, ou seja, como se fomenta reconhecimento do outro a partir de uma visão mais aberta de verdade histórica (FRONZA, 2012).

Nesse sentido, a preocupação com os conceitos de segunda ordem, no Brasil, ainda que apareça em alguns estudos, não se revela no sentido de confiar 
que a progressão da aprendizagem conceitual fomenta uma orientação histórica mais adequada, pois há uma presença significativa da concepção segundo a qual a orientação tem uma relação direta com a interpretação, que por sua vez é alimentada pelas experiências. Ou seja, as experiências culturais e sociais, embasadas em experiências históricas, são elementos determinantes da orientação histórica e a preocupação com essas dimensões diminui a preocupação com a progressão no domínio de conceitos estruturantes.

Um texto de Schmidt (2011), publicado nas XI Jornadas, tenta articular a aproximação entre a filosofia da história de Jörn Rüsen e a filosofia educacional de Paulo Freire, e sinaliza para essa preocupação essencial com as experiências dos sujeitos e a possibilidade de transformação de suas consciências num sentido emancipatório. Segundo a autora, o ponto de partida para a Educação Histórica deveria ser levantar os conhecimentos prévios dos alunos e buscar transformar essas visões num sentido mais complexo, levando os alunos a tomarem consciência e buscarem alternativas transformadoras.

"Aprendizagem histórica não pode ser pensada apenas como aquisição de competências cognitivas" (SCHMIDT, 2011, p. 199), fazendo uma crítica direta à ideia de se estabelecer metas de aprendizagem embasadas nas investigações da Educação Histórica, movimento que já estava sendo realizado em Portugal. Schmidt ainda aponta, inspirada em Paulo Freire, que a educação deve guiar a sociedade no sentido da "eliminação da fome e da miséria", dando uma conotação política muito evidente ao seu posicionamento.

Cainelli e Schmidt (2012), ao apresentarem os desafios teóricos e epistemológicos para a pesquisa em Educação Histórica, apontam “A Educação Histórica atribui uma utilidade e um sentido social ao conhecimento histórico, como por exemplo, a formação da consciência histórica” (2012, p. 503). Já Schmidt e Urban ressaltam que:

O objetivo é uma consciência crítico-genética, onde a relação entre passado e presente seja fundamentada em narrativas mais complexas, que se prestem à uma orientação temporal para a vida presente, baseadas em alguns princípios como a liberdade, democracia e direitos humanos. (SCHMIDT; URBAN, 2018, p. 27) 
Ressalta-se novamente que, no Brasil, a Educação Histórica adquiriu identidade própria, caracterizada por um foco na orientação histórica, permeada pela preocupação com as experiências dos sujeitos e as possibilidades de transformação do conhecimento para suas vidas. Entretanto, diferentemente do que ocorre em Portugal, ficam evidentes algumas concepções políticoideológicas que permeiam as preocupações dos investigadores.

Para finalizar essa análise do percurso da Educação Histórica no Brasil, destacamos o trabalho de Fronza (2016), que busca articular a ideia de perspectividade na interpretação histórica, com a construção das identidades dos jovens, no âmbito do reconhecimento e aceitação das diferenças culturais. Embasado por um novo humanismo, ideia desenvolvida por Jörn Rüsen em seus trabalhos mais recentes (RÜSEN, 2014), Fronza utiliza as histórias em quadrinhos como fontes para promover a aprendizagem histórica e trabalha com a busca por verificar a progressão no domínio de categorias epistemológicas e sua contribuição para a orientação da vida prática dos estudantes.

Ao argumentar sobre a relevância dessa aprendizagem, Fronza indica que:

Ocorre, então, um envolvimento com o tema gerado pela reflexão histórica. Passando por esta "identificação inicial", os jovens teriam que procurar "respostas críticas" na História que possibilitassem ampliação de sua identidade individual ou coletiva. É nesta reflexão crítica, que a intervenção do método histórico tem sua importância para que se superem conclusões subjetivistas e preconceituosas sobre o passado. (FRONZA, 2016, p. 110)

Há, então, no trabalho de Fronza, a ideia de superação do preconceito e construção de uma identidade mais aberta, menos subjetivista, por parte dos estudantes. Nesse intento, a articulação teórica que o investigador realiza contempla as três dimensões da consciência histórica - experiência, interpretação e orientação - com a qualificação da aprendizagem no sentido epistemológico, pela via do trabalho com fontes a partir do confronto entre as concepções de verdade e intersubjetividade. Segundo Fronza:

[...] as operações mentais da consciência histórica expressam sim as diferentes formas de abordagem em relação à multiperspectividade das experiências históricas, à controvérsia das interpretações e à pluralidade de formas de orientação de 
sentido no tempo que constituem as relações intersubjetivas e interculturais no processo de formação histórica da humanidade na qual a iniciação docente está intimamente ligada. [...] Essa consciência possibilita, sim, a construção de critérios humanistas e intersubjetivos que forneçam princípios para a formação de uma identidade histórica baseada na interculturalidade, ou seja, no reconhecimento mútuo das diferenças regidas por uma alteridade igualitária. (FRONZA, 2015, p. 125)

Esse estudo é significativo de uma nova tendência nos estudos da Educação Histórica, principalmente no Brasil, de direcionar as preocupações para os princípios formativos inspirados no novo humanismo, ou da busca pelo reconhecimento da diversidade cultural e da necessidade de resolução de conflitos e do trabalho com temas controversos no ensino de história. Essa influência também é sentida em Portugal, mas com uma adesão mais tímida, como se pode notar no texto de introdução às XVI Jornadas, no qual Isabel Barca (2016) preconiza que a Educação Histórica efetiva propostas de ensino desafiantes e adequadas, numa perspectiva "humanista e contextualizada".

A pesquisa de Fronza (2016) demonstra um esforço inicial por relacionar a progressão da aprendizagem conceitual a determinadas formas de orientação dos sujeitos na vida em sociedade, como no caso da relação entre compreensão da multiperspectividade e desenvolvimento de uma atitude de respeito e tolerância pela diversidade. Mas esse esforço traz algumas constatações que não podem ser generalizadas, pois se trata de um estudo pontual. Seria necessário, portanto, ampliar esse tipo de investigação no sentido de poder trazer constatações que permitissem um maior grau de certeza a respeito dessas possibilidades.

No estágio atual das investigações no Brasil, permanece o paradoxo já levantado e não solucionado. Sendo a orientação histórica informada por experiências subjetivas, preocupar-se prioritariamente com a aprendizagem conceitual pode ser estéril, uma vez que não se garante que esse uso sofisticado ou adequado dos conceitos se reproduzirá na vida dos estudantes, sendo esse ainda um campo de investigações praticamente inexplorado. Mas, se a busca é por definir ideais para a formação histórica, como aceitação e reconhecimento da diversidade cultural, ou uma postura crítica diante dos problemas sociais, corre-se o risco de priorizar esses valores e princípios, conduzindo os processos 
de ensino de forma direcionada, sem explorar os potenciais racionais do pensamento histórico.

\section{Considerações finais: indagações e alternativas para um debate em aberto}

Nossa análise não abarcou todos os textos publicados nos anais das Jornadas de Educação Histórica, por isso diversos pesquisadores que participaram desses eventos e fizeram parte desses grupos de pesquisa não foram citados neste texto. Isso se deve ao fato, como alertamos, de que foi preciso estabelecer uma metodologia para selecionar trabalhos, a partir dos critérios definidos, que se mostrassem mais frutíferos em trazer elementos para análise. Isso permitiu uma análise panorâmica que nos conduziu a importantes constatações sobre as tendências e debates na área, com foco na nossa preocupação de pesquisa, qual seja, a relação entre aprendizagem conceitual, orientação e formação histórica.

Feita essa ressalva, consideramos que nosso estudo contribui para entender os caminhos percorridos pelos estudos da Educação Histórica, em Portugal e no Brasil, observando divergências e convergências. Assim como para identificar avanços e também lacunas, as quais apontamos no sentido de favorecer o avanço das investigações na área e o aprofundamento das suas problemáticas.

Constatamos, então, que os estudos da Educação Histórica em Portugal, no período analisado, foram marcados por algumas características bem definidas, que podemos sintetizar a partir dos seguintes pontos:

1. Uma preocupação recorrente com a ideia de aprendizagem dos conceitos de segunda ordem e uma confiança de que essa aprendizagem tem um potencial em si de contribuir para a orientação histórica e a formação dos sujeitos;

2. Apropriação dos conceitos de consciência histórica e narrativa histórica, mas com adaptações que mantiveram as características do que já vinha sendo desenvolvido, especialmente a partir da noção de se estabelecer níveis de progressão e distintas categorias de análise das ideias dos alunos; 
3. A incorporação da ideia de orientação histórica como um componente entre os objetivos da Educação Histórica, mas sem a definição dos sentidos e das finalidades formativas dessa orientação, oscilando geralmente entre uma defesa tímida de valores gerais (democracia, participação, respeito à diversidade e à interculturalidade) ou de uma confiança nos potenciais racionais da epistemologia da história em fornecer ferramentas "úteis" para a vida em sociedade;

4. Ausência de estudos que evidenciassem correspondência direta entre a apropriação qualificada dos conceitos de segunda ordem e o desenvolvimento de uma "consciência histórica sofisticada", não sendo possivel observar as tomadas de decisões dos sujeitos de acordo com os níveis de domínio de determinados conceitos epistemológicos.

Já com relação aos estudos da Educação Histórica no Brasil, em síntese, constatamos alguns aspectos relevantes:

1. Uma forte influência de outros estudos da área educacional sobre as investigações e debates, especialmente a partir de uma preocupação com o conceito de cultura e com as influências políticas, sociais e culturais sobre a realidade educacional e sobre as experiências de professores e estudantes;

2. A centralidade da ideia de orientação histórica e uma menor preocupação com a aprendizagem conceitual, refletida na indagação recorrente sobre os efeitos sociais da aprendizagem e na busca pela mobilização de uma aprendizagem significativa;

3. Maior adesão aos pressupostos e conceitos dos investigadores alemães, com o gradual distanciamento dos referenciais ingleses e um direcionamento para as preocupações com o conceito de consciência histórica.

4. Intensa presença de conceitos norteadores, como cidadania, emancipação, interculturalidade e humanismo, para definir os objetivos do ensino, em detrimento de uma ideia de maior distanciamento desses objetivos políticos em nome da defesa da aprendizagem histórica como um norte em si. 
Enfim, os aspectos elencados evidenciam a constatação da complexidade na formulação de soluções para a problemática central dessa pesquisa, a relação entre aprendizagem conceitual e orientação histórica. Ainda assim, a ambição de uma formação histórica que contribua de forma significativa e decisiva para a vida social trata-se de um norte elementar da Educação Histórica. Contudo, dado o estágio atual dos estudos na área, o importante é compreender os mecanismos e as bases das proposições e práticas relativas ao ensino que estão vigentes, identificando limites, incoerências e fragilidades.

Nesse percurso investigativo, constatamos que a relação entre a apreensão de conceitos epistemológicos e as apropriações e interpretações que signifiquem a aquisição de disposições para a orientação na vida, intermediadas pelos potenciais racionais desses conceitos, trata-se de um campo empírico a ser explorado, e não de um pressuposto teórico consolidado.

Além disso, não há coesão entre os teóricos no sentido de definir quais são esses conceitos epistemológicos, e que tipo de contribuição dariam para a orientação dos estudantes. Reconhecemos a existência de alguns intentos, mas que não revelam um consenso entre os estudiosos da área, nem se apresentam sob a forma de estudos sistemáticos, que evidenciem que esses conceitos têm o potencial de orientar a vida dos estudantes no sentido dos nortes formativos preconizados, como reconhecimento da alteridade ou predisposição à superação de problemas sociais ou injustiças.

Nosso posicionamento, a princípio, se dá no sentido de compreender que a progressão conceitual é um ganho cognitivo necessário à qualificação das experiências humanas, e isso por si só já sustenta sua defesa como conteúdo educacional. Entretanto, não há ainda elementos para se afirmar que esse ganho cognitivo garanta orientações históricas em sentidos previsíveis ou desejados. Do ponto de vista investigativo, pode-se explorar essa possibilidade, entretanto não corroboramos sua adoção a priori. 


\section{Fontes de Estudo}

BARCA, Isabel (org.). JORNADAS INTERNACIONAIS DE EDUCAÇÃO HISTÓRICA, 1., 2000, Braga. Actas [...]. Braga: CIED: Univ. do Minho, 2001. Tema: Perspectivas em educação histórica.

BARCA, Isabel; GAGO, Marília (orgs.). JORNADAS INTERNACIONAIS DE EDUCAÇÃO HISTÓRICA, 2., 2001, Braga. Actas [...]. Braga: CIED: Univ. do Minho, 2003. Tema: Educação histórica e museus.

BARCA, Isabel; GAGO, Marília (orgs.). JORNADAS INTERNACIONAIS DE EDUCAÇÃO HISTÓRICA, 3., 2003, Braga. Actas [...]. Braga: CIED: Univ. do Minho, 2006. Tema: Questões de epistemologia e investigação em ensino de história.

BARCA, Isabel (org.). JORNADAS INTERNACIONAIS DE EDUCAÇÃO HISTÓRICA, 4., 2004, Braga. Actas [...]. Braga: CIED: Univ. do Minho, 2004. Tema: Para uma educação histórica de qualidade.

BARCA, Isabel; SCHMIDT, Maria A. (orgs.). JORNADAS INTERNACIONAIS DE EDUCAÇÃO HISTÓRICA, 5., 2005, Braga. Actas [...]. Braga: CIED: Univ. do Minho, 2009. Tema: Educação histórica: investigação em Portugal e no Brasil.

SCHMIDT, Maria A.; BRAGA, Tânia M. F. (orgs.). JORNADAS INTERNACIONAIS DE EDUCAÇÃO HISTÓRICA, 6., 2006, Curitiba. Actas [...]. Curitiba: Ed. UTFPR, 2007. Tema: Perspectivas da investigação em educação histórica. 2. v.

BARCA, Isabel (org.). JORNADAS INTERNACIONAIS DE EDUCAÇÃO HISTÓRICA, 7., 2007, Braga. Actas [...]. Braga: CIED: Univ. do Minho, 2008. Tema: Estudos de consciência histórica na Europa, América, Ásia e África.

CAINELLI, Marlene; SCHMIDT, Maria A. M. S. JORNADAS INTERNACIONAIS DE EDUCAÇÃO HISTÓRICA, 10., 2010, Londrina. Atas [...]. Ijuí: Ed. Unijuí, 2011. Tema: Educação histórica: teoria e pesquisa.

BARCA, Isabel (org.). JORNADAS INTERNACIONAIS DE EDUCAÇÃO HISTÓRICA, 11., 2011, Braga. Atas [...]. Braga: CIED: Universidade do Minho, 2011. Tema: Consciência histórica na era da globalização.

SCHMIDT, Maria A. (org.). CONGRESSO INTERNACIONAL JORNADAS DE EDUCAÇÃO HISTÓRICA, 12., 2012, Curitiba. Atas [...]. Curitiba: LAPEDUH - UFPR, 2012. Tema: Consciência histórica e novas tecnologias da informação e comunicação. 
CONGRESSO INTERNACIONAL DAS JORNADAS DE EDUCAÇÃO HISTÓRICA, 13., 2013, Barcelona. Actas [...]. Braga: ClED: Univ. do Minho; Barcelona: Universidad de Barcelona, 2013. Tema: História e identidades culturales.

BARCA, Isabel; ALVES, Luís A. M. Educação histórica: perspectivas de investigação nacional e internacional. Porto: CITCEM: Universidade do Porto, 2016.

RIBEIRO, Cláudia P.; VIEIRA, Helena; BARCA, Isabel; ALVES, Luís Aberto; PINTO, Maria Helena; GAGO, Marília (coords.). JORNADAS INTERNACIONAIS DE EDUCAÇÃO HISTÓRICA, 16., 2016, Porto. [Actas]. Porto: CITCEM: Universidade do Porto, 2017. Tema: Epistemologias e ensino de história.

SOUZA, E der C. (org.). CONGRESSO INTERNACIONAL DAS JORNADAS DE EDUCAÇÃO HISTÓRICA, 13., Foz do Iguaçu. Anais [...]. Foz do Iguaçu: UNILA, 2017. Disponível em: https://www.even3.com.br/anais/jornadaseh2017. Acesso em: 20 jan. 2020. Tema: Teoria, Pesquisa e Prática.

\section{Referências}

ALVES, Ronaldo Cardoso. História e vida: encontro epistemológico entre didática da história e educação histórica. História \& Ensino, Londrina, v.19, n.1, p. 49-69, jan./jun. 2013.

ASHBY, Rosalyn. Conceito de evidência histórica: exigências curriculares e concepções dos alunos. In: BARCA, Isabel; GAGO, Marília (orgs.). Educação histórica e museus: actas das Segundas Jornadas de Educação Histórica. Braga: ClED - Univ. do Minho, 2003. p. 37-58.

AZAMBUJA, Luciano. 'Fado Tropical': protonarrativas de jovens alunos brasileiros e portugueses, escritas a partir das leituras e escutas de uma canção 'engajada'. In: CAINELLI, Marlene; SCHMIDT, Maria Auxiliadora. Educação histórica: teoria e pesquisa. Ijuí: Ed. Unijuí, 2011.

BARCA, Isabel. Educação histórica: uma nova área de investigação. Revista da Faculdade de Letras: História, Porto, série 3, v. 2, p. 13-21, 2001 .

BARCA, Isabel. Concepções de adolescentes sobre múltiplas explicações em História. In: BARCA, Isabel (org.). JORNADAS INTERNACIONAIS DE EDUCAÇÃO HISTÓRICA, 1., 2000, Braga. Actas [...]. Braga: CIED: Univ. do Minho, 2001b. Tema: Perspectivas em educação histórica. p. 29-44. 
BARCA, Isabel. Aula oficina: do projecto à avaliação. In: BARCA, Isabel (org.). JORNADAS INTERNACIONAIS DE EDUCAÇÃO HISTÓRICA, 4., 2004, Braga. Actas [...]. Braga: CIED: Univ. do Minho, 2004. Tema: Para uma educação histórica de qualidade. p. 131-145.

BARCA, Isabel. Em torno da epistemologia da História. In: BARCA, Isabel; GAGO, Marília (orgs.). JORNADAS INTERNACIONAIS DE EDUCAÇÃO HISTÓRICA, 3., 2003, Braga. Actas [...]. Braga: CIED: Univ. do Minho, 2006. Tema: Questões de epistemologia e investigação em ensino de história. p. 17-26.

BARCA, Isabel. Estudos de consciência histórica em Portugal: perspectivas de jovens portugueses acercada da Históira. In: BARCA, Isabel (org.). JORNADAS INTERNACIONAIS DE EDUCAÇÃO HISTÓRICA, 7., 2007, Braga. Actas [...]. Braga: CIED: Univ. do Minho, 2008. Tema: Estudos de consciência histórica na Europa, América, Ásia e África. p. 47-54.

BARCA, Isabel. O papel da educação histórica no desenvolvimento social. In: CAINELLI, Marlene; SCHMIDT, Maria Auxiliadora. Educação histórica: teoria e pesquisa. ljuí: Ed. Unijuí, 2011. p. 21-48.

BARCA, Isabel. Consciência histórica de jovens: identidade, mudança em história e sentidos para vida. Cadernos de Pesquisa: Pensamento Educacional, Curitiba, v.9, n. 21, p. 86-107. jan./abr. 2014.

BARCA, Isabel; ALVES, Luís A. M. (orgs). Educação histórica: perspectivas de investigação nacional e internacional. Porto: CITCEM: Universidade do Porto, 2016.

CASTRO, Julia. Consciência histórica e interculturalidade: dos pressupostos teóricos à investigação sobre as ideias de jovens portugueses. In: BARCA, Isabel (org.). JORNADAS INTERNACIONAIS DE EDUCAÇÃO HISTÓRICA, 7., 2007, Braga. Actas [...]. Braga: CIED: Univ. do Minho, 2008. Tema: Estudos de consciência histórica na Europa, América, Ásia e África. p. 65-74.

CASTRO, Julia. 'Gente em movimento ao longo do tempo': interculturalidade e consciência histórica segundo jovens portugueses. In: BARCA, Isabel (org.). JORNADAS INTERNACIONAIS DE EDUCAÇÃO HISTÓRICA, 11., 2011, Braga. Atas [...]. Braga: CIED: Universidade do Minho, 2011. Tema: Consciência histórica na era da globalização. p. 25-35.

DGIDC. Metas de aprendizagem online. [Lisboa]: Ministério da Educação, 2010. Disponível em: http://www.metasdeaprendizagem.min-edu.pt/ensinobasico/metasde-aprendizagem/metas/?area=5\&level=6. Acesso em: 18 dez. 2018. 
DIAS, Paula; SOLÉ, Glória. As metas de aprendizagem e a educação histórica: contributos para uma Educação Histórica de qualidade na Era da Globalização. In: BARCA, Isabel (org.). JORNADAS INTERNACIONAIS DE EDUCAÇÃO HISTÓRICA, 7., 2007, Braga. Actas [...]. Braga: CIED: Univ. do Minho, 2008. Tema: Estudos de consciência histórica na Europa, América, Ásia e África. p. 65-109.

FERNANDES, Lindamir Z. A conquista dos direitos da mulher e seu significado para os alunos e suas famílias. In: SCHMIDT, Maria A.; BRAGA, Tânia M. F. (orgs.). JORNADAS INTERNACIONAIS DE EDUCAÇÃO HISTÓRICA, 6., 2006, Curitiba. Actas [...]. Curitiba: Ed. UTFPR, 2007. Tema: Perspectivas da investigação em educação histórica. v. 1. p.43-51.

FONSECA, Clarissa. O papel da empatia histórica na compreensão do outro. In: BARCA, Isabel; SCHMIDT, Maria A. (orgs.). JORNADAS INTERNACIONAIS DE EDUCAÇÃO HISTÓRICA, 5., 2005, Braga. Actas [...]. Braga: CIED: Univ. do Minho, 2009. Tema: Educação histórica: investigação em Portugal e no Brasil. p. 115-130.

FREITAS, Itamar. Aprender e ensinar história nos anos finais da escolarização básica. Aracaju: Criação, 2014.

FRONZA, Marcelo. As ideias de objetividade e verdade no pensamento histórico dos jovens a partir das histórias em quadrinhos. In: CAINELLI, Marlene; SCHMIDT, Maria Auxiliadora. Educação histórica: teoria e pesquisa. Ijuí: Ed. Unijuí, 2011.

FRONZA, Marcelo. A intersubjetividade e a verdade na aprendizagem histórica de jovens estudantes a partir das histórias em quadrinhos. 2012. 478 p. Tese (Doutorado em Educação) - Programa de Pós-Graduação em Educação, Universidade Federal do Paraná, Curitiba, 2012. 478 p.

FRONZA, Marcelo. As ideias de jovens estudantes sobre a conquista da América a partir do conflito entre europeus e indígenas nas histórias em quadrinhos de Altan e do livro didático de história de Julierme: interculturalidade e consciência histórica na busca por uma perspectiva humanista. In: RIBEIRO, Cláudia P.; VIEIRA, Helena; BARCA, Isabel; ALVES, Luís Aberto; PINTO, Maria Helena; GAGO, Marília. Epistemologias e ensino de história. Porto: CITCEM: Universidade do Porto, 2017. p. 105-127.

GAGO, Marília. Olhar de alunos acerca da variância da narrativa histórica. In: BARCA, Isabel; GAGO, Marília (orgs.). JORNADAS INTERNACIONAIS DE EDUCAÇÃO HISTÓRICA, 3., 2003, Braga. Actas [...]. Braga: CIED: Univ. do Minho, 2006. Tema: Questões de epistemologia e investigação em ensino de história. p. 55-73. 
GAGO, Marília. A identidade do "eu" e do "nós". In: BARCA, Isabel (org.). JORNADAS INTERNACIONAIS DE EDUCAÇÃO HISTÓRICA, 7., 2007, Braga. Actas [...]. Braga: CIED: Univ. do Minho, 2008. Tema: Estudos de consciência histórica na Europa, América, Ásia e África. p. 55-65.

GAGO, Marília. O sentido do tempo ou o tempo com sentido (s)? Ideias dos alunos acerca de identidade e orientação temporal. In: BARCA, Isabel (org.). JORNADAS INTERNACIONAIS DE EDUCAÇÃO HISTÓRICA, 11., 2011, Braga. Atas [...]. Braga: CIED: Universidade do Minho, 2011. Tema: Consciência histórica na era da globalização.

p. 36-47.

GARCIA, Tânia Braga. Estudos sobre consciência histórica na Universidade Federal do Paraná. In: BARCA, Isabel (org.). JORNADAS INTERNACIONAIS DE EDUCAÇÃO HISTÓRICA, 7., 2007, Braga. Actas [...]. Braga: CIED: Univ. do Minho, 2008. Tema: Estudos de consciência histórica na Europa, América, Ásia e África. p. $123-134$.

GERMINARI, Geyso D. Educação histórica: a constituição de um campo de pesquisa. Revista HISTED-BR on-line, Campinas, n.42, p.54-70, 2011.

GERMINARI, Geyso D. Consciência Histórica de jovens escolarizados e história da cidade. In: CAINELLI, Marlene; SCHMIDT, Maria Auxiliadora. Educação histórica: teoria e pesquisa. Ijuí: Ed. Unijuí, 2011. p. 91-104.

KÖRBER, Andreas. Translations and its discontents II: a german perspective. Journal of Currículum Studies, v. 48, n. 4, p. 440-456, 2016.

LEE, Peter; ASHBY, Rosalyn; DICKINSON, Alaric. Progression in children's ideas about History. In: HUGHES, Martin (ed.). Progression in learning. Clevedon: Multilingal Matters, BERA Dialogues II, 1996, p.50-81.

LEE, Peter; DICKINSON, Alaric; ASHBY, Rosalyn. Researching children's ideas about history. In: VOSS, James F.; CARRETERO, Mario. International review of history education: learning and reasoning in history. London: Routledge, 1998. v. 2. p. 227-251.

LEE, Peter. Em direção a um conceito de Literacia Histórica. Educar, Curitiba, p. 131-150, 2006. Número especial.

LEE, Peter. Educação histórica, consciência histórica e literacia histórica. In BARCA, Isabel (org.). JORNADAS INTERNACIONAIS DE EDUCAÇÃO HISTÓRICA, 7., 2007, Braga. Actas [...]. Braga: CIED: Univ. do Minho, 2008. Tema: Estudos de consciência histórica na Europa, América, Ásia e África. p. 11-32. 
MAGALHÃES, Olga. Entre passado e presente: perspectivas de alunos portugueses. In: SCHMIDT, Maria A.; BRAGA, Tânia M. F. (orgs.). JORNADAS INTERNACIONAIS DE EDUCAÇÃO HISTÓRICA, 6., 2006, Curitiba. Actas [...]. Curitiba: Ed. UTFPR, 2007. Tema: Perspectivas da investigação em educação histórica. v. 1. p. 103-111.

PARENTE, Regina. A narrativa na aula de história. In: BARCA, Isabel; SCHMIDT, Maria A. (orgs.). JORNADAS INTERNACIONAIS DE EDUCAÇÃO HISTÓRICA, 5., 2005, Braga. Actas [...]. Braga: ClED: Univ. do Minho, 2009. Tema: Educação histórica: investigação em Portugal e no Brasil. p. 79-113.

PINTO, Maria Helena. A melhor forma de conhecer Guimarães é ir explorar: compreensão histórica de alunos portugueses sobre evidência patrimonial. In: CAINELLI, Marlene; SCHMIDT, Maria Auxiliadora. Educação histórica: teoria e pesquisa. ljuí: Ed. Unijuí, 2011.

RÜSEN, Jörn. Razão histórica: teoria da história: os fundamentos da ciência histórica. Trad. Estevão C. de Rezende Martins. Brasília: UNB, 2001.

RÜSEN, Jörn. Aprendizagem histórica: fundamentos e paradigmas. Curitiba: W.A. Editores, 2012.

RÜSEN, Jörn. Cultura faz sentido: orientações entre o ontem e o amanhã. Trad. Nélio Schneider. Petrópolis: Vozes, 2014.

SCHMIDT, Maria Auxiliadora. Perspectivas de investigação em Educação Histórica na Universidade Federal do Paraná. In: BARCA, Isabel (org.). JORNADAS INTERNACIONAIS DE EDUCAÇÃO HISTÓRICA, 7., 2007, Braga. Actas [...]. Braga: CIED: Univ. do Minho, 2008. Tema: Estudos de consciência histórica na Europa, América, Ásia e África. p. 109-122.

SCHMIDT, Maria Auxiliadora. A cultura como referência para investigação sobre consciência histórica: diálogos entre Paulo Freire e Jörn Rüsen. In: BARCA, Isabel (org.). JORNADAS INTERNACIONAIS DE EDUCAÇÃO HISTÓRICA, 11., 2011, Braga. Atas [...]. Braga: CIED: Universidade do Minho, 2011. Tema: Consciência histórica na era da globalização. p. 191-200.

SCHMIDT, Maria Auxiliadora; GARCIA, Tânia Braga. Pesquisas em Educação Histórica: Algumas experiências. Educar, Curitiba, p. 11-31, 2006. Número especial. 
SCHMIDT, Maria Auxiliadora; GARCIA, Tânia Braga. O trabalho com objetos e as possibilidades de superação do sequestro da cognição histórica: estudo de caso com crianças nas séries iniciais. In: SCHMIDT, Maria A.; BRAGA, Tânia M. F. (orgs.). JORNADAS INTERNACIONAIS DE EDUCAÇÃO HISTÓRICA, 6., 2006, Curitiba. Actas [...]. Curitiba: Ed. UTFPR, 2007. Tema: Perspectivas da investigação em educação histórica. v. 1. p. 52-67.

SCHMIDT, Maria Auxiliadora; GARCIA, Tânia Braga. Investigando para ensinar História: contribuições de uma pesquisa em colaboração. In: BARCA, Isabel; SCHMIDT, Maria A. (orgs.). JORNADAS INTERNACIONAIS DE EDUCAÇÃO HISTÓRICA, 5., 2005, Braga. Actas [...]. Braga: CIED: Univ. do Minho, 2009. Tema: Educação histórica: investigação em Portugal e no Brasil. p. 29-44.

SCHMIDT, Maria Auxiliadora; CAINELLI, Marlene. Desafios teóricos e epistemológicos nas pesquisas em Educação Histórica. Antíteses, Londrina. v. 5, n.10, p. 509-518, jul./dez. 2012.

SCHMIDT, Maria Auxiliadora; URBAN, Ana Claudia. Afinal, o que é educação histórica? RIBEH, Curitiba, v.1, n. 01, p. 07-31, ago./dez. 2018.

SIMÃO, Ana C. A importância da evidência Histórica na construção do conhecimento histórico. In: CAINELLI, Marlene; SCHMIDT, Maria A. M. S. JORNADAS INTERNACIONAIS DE EDUCAÇÃO HISTÓRICA, 10., 2010, Londrina. Atas [...]. Ijuí: Ed. Unijuí, 2011. Tema: Educação histórica: teoria e pesquisa. p. 181-198.

SIMÃO, Ana C.; BARCA, Isabel. A construção da evidência histórica e as metas de aprendizagem. In: BARCA, Isabel (org.). JORNADAS INTERNACIONAIS DE EDUCAÇÃO HISTÓRICA, 11., 2011, Braga. Atas [...]. Braga: CIED: Universidade do Minho, 2011. Tema: Consciência histórica na era da globalização. p. 48-64.

SOUZA, Eder C. Educação histórica e multiperspectividade: uma proposta de trabalho com o conceito substantivo Nazismo a partir de fontes fílmicas diversificadas. In: SCHMIDT, Maria A. (org.). CONGRESSO INTERNACIONAL JORNADAS DE EDUCAÇÃO HISTÓRICA, 12., 2012, Curitiba. Atas [...]. Curitiba: LAPEDUH - UFPR, 2012. Tema: Consciência histórica e novas tecnologias da informação e comunicação. p. 194-205.

SOUZA, Eder C. Cinema e educação histórica: jovens e suas relações com a história em filmes. 2014. 357 p. Tese (Doutorado em Educação) - Programa de Pós Graduação em Educação -Universidade Federal do Paraná, Curitiba, 2014. 
THEOBALD, Henrique R. A Educação Histórica e a mudança de paradigma na cultura escolar do município de Araucária - PR. In: BARCA, Isabel; SCHMIDT, Maria A. (orgs.). JORNADAS INTERNACIONAIS DE EDUCAÇÃO HISTÓRICA, 5., 2005, Braga. Actas [...]. Braga: ClED: Univ. do Minho, 2009. Tema: Educação histórica: investigação em Portugal e no Brasil. p. 131-138.

VON BORRIES, Bodo. Competence of the historical thinking, mastering of a historical framework, or knowledge of historical canon? In: SYMCOX, Linda; WILSCHUT, Arie. National history standards: the problem of the canon and the future of teatching history. [Charlotte: Information Age Publishing], 2009. p. 283306. (International review of history education, v. 5). 